\title{
Effect of Ball Milling Process on the in Situ Synthesis of Nano-TiB Whiskers
}

\author{
Liu Liping ${ }^{1,2}, \quad$ Liu Yongbing ${ }^{1}, \quad$ Ji Lianfeng ${ }^{1}, \quad$ Cao Zhanyi ${ }^{1}, \quad$ Yang Xiaohong ${ }^{1}$ \\ ${ }^{1}$ Key Laboratory of Automobile Materials, Ministry of Education, Jilin University, Changchun 130025, China; ${ }^{2}$ Changchun Vocational Institute \\ of Technology, Changchun 130033, China
}

\begin{abstract}
Ball milling process has an important effect on the microstructure and the morphology of final powder products and the corresponding as-sintered samples. In the present study, Ti-7Al-0.2B (wt\%) mixed powder was ball-milled by low-energy and high-energy types of ball mills, and then the milled powder was sintered by hot-pressing. On this basis, the morphology evolution of the powder was analyzed, and the microstructures of the reinforcements in the as-sintered composite were investigated. Research results show that in the low-energy ball milling process, mechanical alloying occurs between the powder particles. TiB whiskers formed in sintering process are long and thin without linked coarse crystals bars or clusters. Under the high-energy milling, the average particle size of the powder is refined remarkably to $1 \mu \mathrm{m}$, and $\mathrm{Ti}(\mathrm{Al})$ supersaturated solid solution or even amorphous structure is formed during the milling process. In the following sintering process, nano-scale TiB whiskers are synthesized and they are uniformly distributed in the matrix.
\end{abstract}

Key words: ball milling; hot pressed sintering; TiB whisker

Titanium matrix composites (TMCs) are considered as potential materials for advanced automotive, military and aerospace applications because of their low density, high strength and superior elevated temperature properties. Compared with continuous fiber reinforced composites, discontinuous particles or whiskers reinforced titanium based composites show more promising prospects for practical applications since they are isotropic, cost-effective and easy to fabricate ${ }^{[1-3]}$

In the commonly used discontinuous reinforcements, $\mathrm{TiB}$ synthesized by in situ process is suggested to be an ideal reinforcement in titanium matrix due to their excellent capabilities, such as strong interface bonding with matrix, thermal stability at high temperature and similar coefficient of thermal expansion to titanium. TiB reinforced titanium based composites can be fabricated by several methods including casting, powder metallurgy and SHS (self propagation high temperature synthesis) technologies ${ }^{[4-6]}$. However, many undesired coarse particles and clusters sometimes appear in the composites, which may act as the source of cracks and dramatically lower the mechanical properties of the composites. Hence, it is very crucial to reduce the size of reinforcements for improving the mechanical properties of TMCs.

Ball milling is a powerful and cost-effective powder processing technique for grain size reduction and alloy synthesis. However, the final products of milling are significantly affected by various parameters of milling process H. B. Feng et al. ${ }^{[7]}$ investigated the influences of several factors including milling time, different powder mixtures, process control agent (PCA), ball size and rotating speed, but they ignored one important parameter of mechanical alloying (MA), i.e., the type of ball mill. In the present study, two different types of ball mills were used to perform ball milling processes on Ti-7Al-0.2B (wt\%) mixed powder. The morphology evolution of powders during ball milling processes was analyzed and the characteristics of in situ synthesized reinforcements in the as-sintered composites were investigated.

\section{Received date: May 4, 2015}

Foundation item: National Natural Science Foundation of China (201215026)

Corresponding author: Yang Xiaohong, Ph. D., Researcher, Key Laboratory of Automobile Materials, Ministry of Education, Department of Materials Science and Engineering, Jilin University, Changchun 130025, P. R. China, Tel: 0086-431-84602956, E-mail: xhyang@jlu.edu.cn 


\section{Experiment}

In the present experiment, Ti powder with an average size of $25 \mu \mathrm{m}$ (purity $>99.5 \%$, irregular), Al powder with an average size of $75 \mu \mathrm{m}$ (purity $>99.5 \%$, spherical) and B powder with an average size of $5 \mu \mathrm{m}$ (purity $>99.5 \%$, irregular) were mixed with a nominal composition of Ti-7Al-0.2B in wt $\%$. The ball-to-powder mass ratio was $10: 1$, and the powders were ball milled in two different types of ball mills. One was the QM-ISP04 horizontal planetary ball mill with a speed of $160 \mathrm{r} / \mathrm{min}$ where the powders were milled for $40 \mathrm{~h}$, hereafter referred to as low-energy milling. And the other was the double pendulum vibrating ball mill with a speed of 550 $\mathrm{r} / \mathrm{min}$ where the powders were milled for $20 \mathrm{~h}$, hereafter referred to as high-energy milling. During milling process, the ball mill was stopped every $5 \mathrm{~h}$ in order to take out a small quantity of powders for characterization and meanwhile to cool down the vial to prevent increasing temperature.

In above mixing and milling processes, the powders were protected by Ar to avoid contamination. Both milled powders were sintered by hot-pressing in vacuum at $1100{ }^{\circ} \mathrm{C}, 20 \mathrm{MPa}$ for $1 \mathrm{~h}$. As a reference, the powder blended for $1 \mathrm{~h}$ in the planetary ball mill without milling was also sintered.

The morphology evolution of the milled powders was studied by X-ray diffraction and DSC analysis. The microstructures of the powder particles and sintered composites were studied by scanning electron microscope (SEM) and transmission electron microscope (TEM).

\section{Results and Discussion}

\subsection{Morphology evolution of the powders}

Fig.1 shows the SEM images of milled powders. As can be seen from Fig.1a, after low-energy milling for $40 \mathrm{~h}$, the morphology of powders is turned into an approximately equiaxed shape from the original irregular shape. The average particle size is $6 \sim 8 \mu \mathrm{m}$, which is less than that of starting powders $(25 \mu \mathrm{m})$. Besides, the sharp edges and corners of the original powders are also polished. Generally, there are two main processes during MA, i.e., particles breaking and cold welding. In the present experiment, cold welding does not lead to an obvious aggregation owing to the low energy ball milling, as well as the limited change of the mixed powders size; only those thinner edges and corners or particles with bigger aspect ratio are fractured during the ball milling process.

Compared with the low-energy ball milled powder, the powder after high-energy ball milling for $20 \mathrm{~h}$ shows a sharp decline in particle size. As shown in Fig.1b, the powder particles are roughly spherical, and their average size is less than $1 \mu \mathrm{m}$. During the ball milling process, the particles sizes of powders experience a typical evolution, namely dramatic increase at the early stage, gradual decrease after a certain time and achieving a stable level at last. This result agrees well with the conclusions in previous reports ${ }^{[8,9]}$. At the early stage, high energy colliding and squeezing of ball/ball and ball/wall result in a severe plastic deformation of the powders and the deformed particles are cold-welded to large lamellar composite particles, which are usually much coarser than the original powders. With the extension of milling time, the composite particles suffer from continuously repeated process of deforming, cold-welding, agglomerating and fracturing caused by the colliding of high-energy balls, so that the powders are refined and gradually transformed to spherical shape. When the effects of cold-welding and fracturing achieve an equilibrium state, the particles size would not change further.

\subsection{Structural evolution of the powders}

Fig.2 shows the TEM images and selected area diffraction patterns of the powder milled for $40 \mathrm{~h}$ in low-energy mill. The selected area diffraction patterns confirm the existence of $\mathrm{TiB}$ and $\mathrm{TiB}_{2}$ phases. That is to say, $\mathrm{TiB}$ and $\mathrm{TiB}_{2}$ are mechanical alloyed during the milling process. From the chemical reaction Eqs. (1) to (3), it can be seen that $\mathrm{TiB}$ is formed by the reaction of $\mathrm{Ti}$ and $\mathrm{B}$ or by the decomposition of $\mathrm{TiB}_{2}$. Turkdogan calculated the thermodynamic data of the reactions ${ }^{[10]}$ :

$$
\begin{array}{ll}
\mathrm{Ti}+\mathrm{B} \rightarrow \mathrm{TiB} & \Delta G=-163176+5.86 T \\
1 / 2 \mathrm{Ti}+\mathrm{B} \rightarrow 1 / 2 \mathrm{TiB}_{2} & \Delta G=-142256+10.25 T \\
\mathrm{Ti}+\mathrm{TiB}_{2} \rightarrow 2 \mathrm{TiB} & \Delta G=-41840-8.79 T
\end{array}
$$

According to thermodynamic theory, one prerequisite of a chemical reaction is that the Gibbs free energy $(\Delta G)$ is negative. The more negative $\Delta G$ means the reaction is easier to occur. Eqs. (1) to (3) show that the $\Delta G$ in the lower temperature range of ball milling process are all negative, indicating these three actions are all possible to occur in the present experiment.

The generation of $\mathrm{TiB}$ and $\mathrm{TiB}_{2}$ reflects the characteristics of collision-induced reactions between elemental powders during

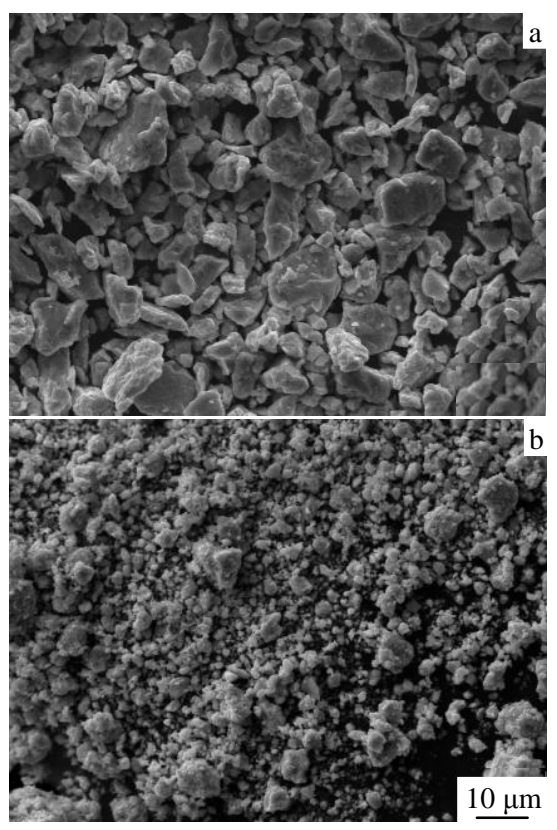

Fig.1 SEM images of the milled powders: (a) low-energy milled for $40 \mathrm{~h}$ and (b) high-energy milled for $20 \mathrm{~h}$ 


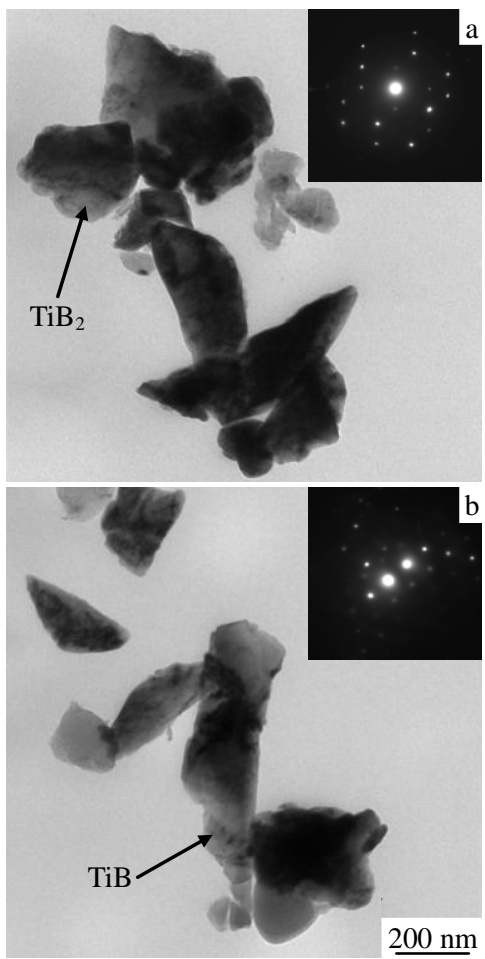

Fig.2 TEM images and the selected-area diffraction patterns of the low-energy milled powder: (a) $\mathrm{TiB}_{2}$ and (b) $\mathrm{TiB}$

the milling process. The mechanism is similar to the reaction mode of $\mathrm{TiC}$ and $\mathrm{NiAl}$ system, that is, the so-called self-propagation high-temperature synthesis (SHS). Since the content of B is very low $(0.2 \mathrm{wt} \%)$ in the experiment, B element is generally dispersed in the excessive titanium. So, even if the powder particles in critical state can be "lighted" by collision at a moment, the reaction would end soon, which cannot form a spread trend.

The selected area diffraction patterns of AlTi were observed too, indicating there are other compounds synthesized. For the powder milled in the low-energy mill, the characteristic peaks of above $\mathrm{B} / \mathrm{Ti}$ and $\mathrm{Al} / \mathrm{Ti}$ compounds do not appear in the X-ray diffraction patterns, indicating the little amount of new formed phases. This could be supported by thermal analysis of the powders in Fig.3. As can be seen, the DSC curves of the powders before and after low-energy milling for $40 \mathrm{~h}$ follow the same trend and present a clear exothermic peak at about $660{ }^{\circ} \mathrm{C}$. By Ti-Al binary phase diagram, Ti reacts with $\mathrm{Al}$ to form $\mathrm{Al}_{3} \mathrm{Ti}$ at about $660{ }^{\circ} \mathrm{C}$. Obviously, this exothermic peak is formed by the reaction heat of $\mathrm{Al}_{3} \mathrm{Ti}$. Thus, it can be concluded that, after $40 \mathrm{~h}$ low-energy milling, only trace compounds are formed while most powders are remained in elemental states.

For the powder milled in the high-energy mill, B/Ti and Al/Ti compounds could also be observed by TEM, but they were invisible in the X-ray diffraction patterns as well.

Fig. 4 shows the XRD patterns of Ti-7Al-0.2B powder after high-energy milling for different time. For the as-blended

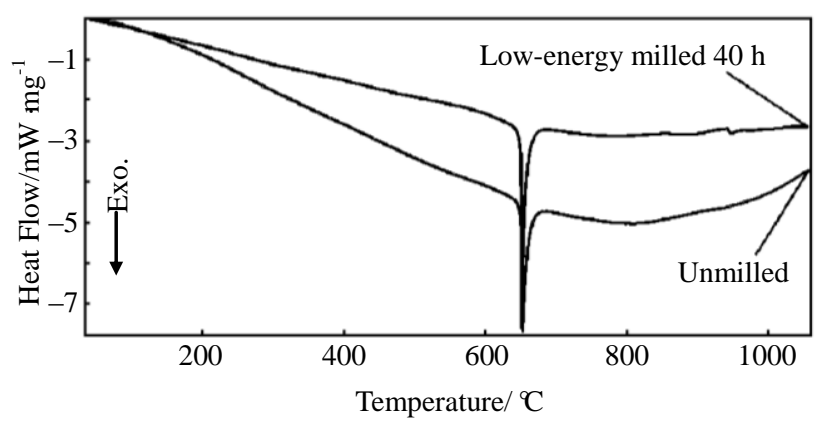

Fig.3 DSC curves of the powders before and after low-energy ball milling

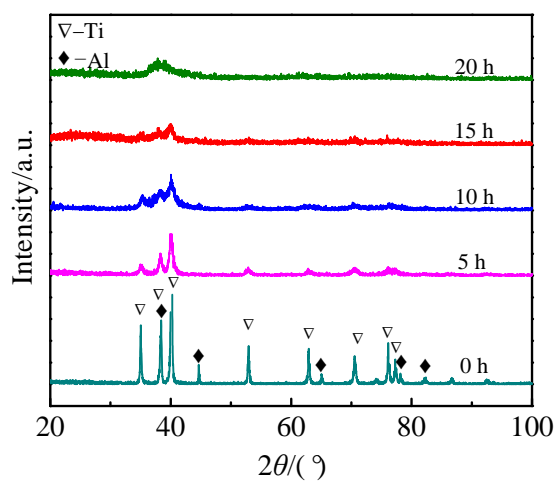

Fig.4 XRD patterns of powders after high-energy ball milling

powder, the diffraction peaks of $\mathrm{Ti}$ and $\mathrm{Al}$ are sharp and narrow. After $5 \mathrm{~h}$ high-energy milling, the peaks are weakened and broadened obviously. There are two main reasons for this result: one is the refinement of the powder particles caused by repeated cold-welding and fracture during MA process, and the other is the internal strain of the deformed particles induced by the continually colliding and grinding of the balls. Notably, another distinct characteristic of the patterns is the disappearance of diffraction peaks of $\mathrm{Al}$ element. Since the refining effect of the powder particles is not very significant at this time, it should be attributed to the dissolution of $\mathrm{Al}$ in Ti.

Fig. 5 shows the DSC curves of powders before and after 10 $\mathrm{h}$ high-energy milling. After milling for $10 \mathrm{~h}$, the sharp exothermic peak of reaction heat between $\mathrm{Ti}$ and $\mathrm{Al}$ disappears, suggesting that $\mathrm{Al}$ is not in elemental state at that time. In addition, there are no other reactions or phase transformations in the whole testing range, which further confirms that $\mathrm{Al}$ element is diffused into Ti lattice and $\mathrm{Ti}(\mathrm{Al})$ supersaturated solid solution is formed.

With the increase of milling time, the diffraction peaks are continuously broadened, owing to the refinement of particles and the accumulation of defects and internal stress in the particles. After milled for $15 \mathrm{~h}$, the diffraction pattern shows the emergence of amorphous phase; after milled for $20 \mathrm{~h}$, the pattern is transformed into a typical "hill" peak, indicating an 


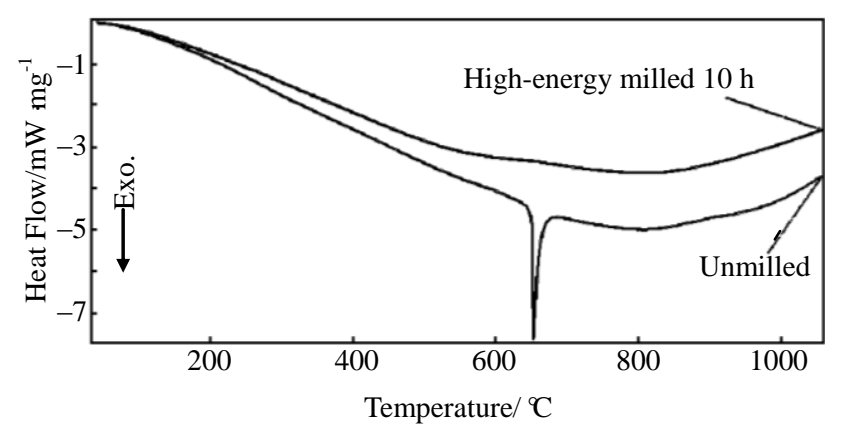

Fig.5 DSC curves of powders before and after high-energy ball milling

amorphous phase is formed.

In order to further identify the amorphous structure, TEM observation was performed on the powders after $20 \mathrm{~h}$ high-energy milling. The selected area electron diffraction in Fig.6 presents the typical halo of amorphous structure, thus confirming the formation of an amorphous phase during ball milling process.

Several studies were conducted on the formation of amorphous Ti-Al phase during ball milling process, but the conclusions are inconsistent. Fan et al. reported that the $\mathrm{Ti}$ content range for amorphous Ti-Al formation was 37 at $\%$ 71 at ${ }^{[11]}$, while Suryanarayana et al. declared that the range was 24 at\% 50 at\% ${ }^{[12]}$. Cocco et al. did a theoretical calculation using Miedema model and suggested the range should be 28 at $\% \sim 77$ at $\%^{[13]}$. In the present Ti-Al system, the Ti content was determined to be about 88 at\% (ignoring the trace B), which does not fall in the range of any above mentioned range.

On the formation mechanism of an amorphous structure during ball milling process, there are several different interpretations. Eckert $\mathrm{J}$ et al. reported that the amorphous phase was formed by the fast cooling of partially melted area of powder particles ${ }^{[14]}$. C. C. Koch considered that the diffusion between layer structures of the metal particles induced solid state reaction and caused the amorphous transition ${ }^{[15]}$. Fecht inferred that the supersaturated solid solutions formed in the

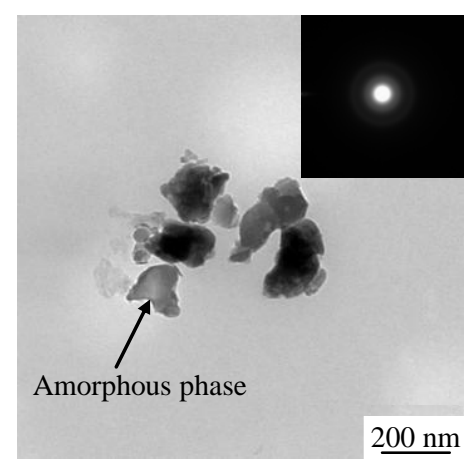

Fig.6 TEM image of high-energy milled powders and selected-area diffraction pattern
MA process lost their stability and transformed into amorphous phase ${ }^{[16]}$. In the present experiment, the MA process was carried out by a vibration type of high-energy ball mill, and the impact of milling balls on the powders is serious. For the ductile $\mathrm{Ti}$ and $\mathrm{Al}$ particles, cold-welding effect is strong, so that the powder particles are gathered into larger lamellar composite particles at the former stage of ball milling process. This kind of multilayer structure will lead to the diffusion of Al-Ti. Moreover, under the effects of severe colliding and grinding, the powder particles are fractured and refined continuously, accompanied by the increase of fresh surfaces and the surface energy. As a result, the diffusion speed between elements is accelerated, and $\mathrm{Ti}(\mathrm{Al})$ supersaturated solid solution is gradually formed. As ball milling process proceeds, a large number of micro defects such as dislocations and lattice distortions are accumulated in the surfaces and interiors of particles. When the energy is accumulated to a critical level, the structure of solid solution becomes unstable, and its crystalline structure changes from distortion to amorphous state.

\subsection{Microstructures of $\mathrm{TiB}$ in the composites}

Ball milling process always has a significant effect on the microstructures of the as-sintered samples. As shown in Figs.7a 7c, TiB, the white phase, is in situ synthesized in all the three as-sintered samples in sintering process. The TiB phase was determined by TEM image and selected area diffraction pattern as shown in Fig.7d. The matrix microstructures of the three composites are all $\mathrm{Ti}(\mathrm{Al})$ solid solution, but the morphology and distribution of the TiB are obviously different.

For the as-sintered sample prepared from unmilled powder (Fig.7a), the sizes of TiB whiskers are uneven with the diameter ranging from $100 \mathrm{~nm}$ to $3 \sim 5 \mu \mathrm{m}$. As indicated by arrows, coarse bars and clusters are also observed in this sample. This is owing to that the powders are very difficult to achieve a remarkably uniform distribution in mixing process; meanwhile, B particles also have various sizes. As a result, $\mathrm{TiB}$ usually grow into coarse bars or clusters in the $\mathrm{B}$ rich region in the process of reaction sintering.

Fig. $7 \mathrm{~b}$ shows the morphology of the sample sintered from low-energy milled powder. TiB whiskers in the sample are uniformly distributed with an even diameter less than $1 \mu \mathrm{m}$, and no coarse bars or clusters are observed. These whiskers are thin and long, with high aspect ratios of more than 60 . This result shows that after $40 \mathrm{~h}$ low-energy ball milling, B particles have been distributed uniformly in the mixed powder. Hence, coarse bars or clusters are eliminated, and the different sizes of $\mathrm{TiB}$ should be attributed to the different sizes of B particles before reaction.

Fig.7c shows the microstructure of samples sintered from 20 h high-energy milled powder. The TiB whiskers are very thin and the average diameter is about $100 \mathrm{~nm}$. The nano-whiskers are randomly oriented and uniformly dispersed in the matrix, which is desirable for reinforcement. During high-energy ball milling process, the $\mathrm{B}$ particles are extremely refined and 


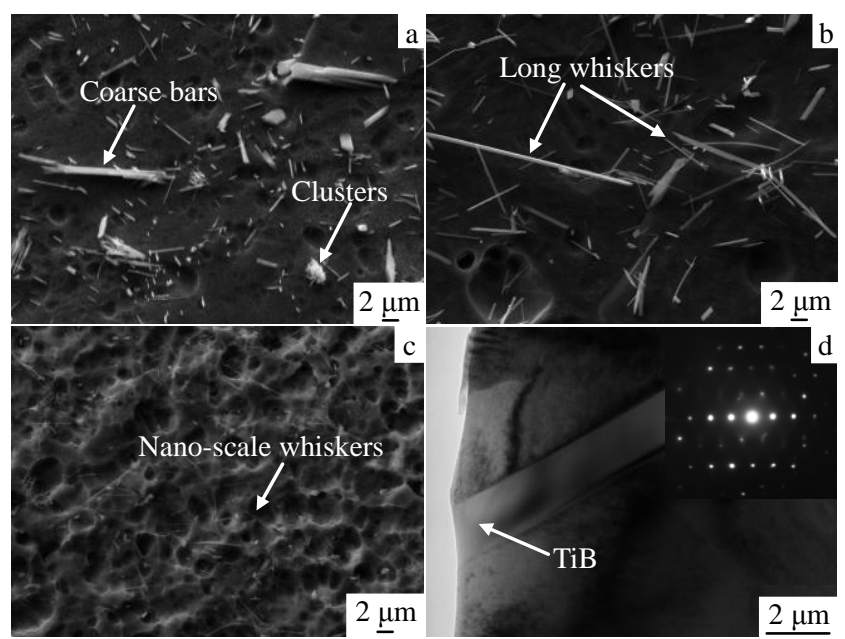

Fig.7 SEM images of as-sintered samples sintered from unmilled powder (a), $40 \mathrm{~h}$ low-energy milled powders (b), and $20 \mathrm{~h}$ high-energy milled powder (c); (d) TEM image of TiB and selected-area diffraction pattern

homogenized in the mixed powder, so that tiny B particles could react with the excessive Ti in sintering; thus dispersed and fine whiskers is formed.

\section{Conclusions}

1) Mechanical alloying occurs in both low-energy and high-energy ball milling processes. Ti(Al) solid solution is formed after $10 \mathrm{~h}$ high-energy milling, and amorphous phase could be observed after $20 \mathrm{~h}$ high-energy milling.

2) In low-energy milling process, TiB whiskers synthesized in sintering process are thin and long and evenly distributed in the matrix. The diameters of most whiskers are less than $1 \mu \mathrm{m}$. Coarse TiB bars and clusters are eliminated.

3) In high-energy milling process, TiB whiskers synthesized in sintering process are very fine with uniform distribution. The diameters of most whiskers are about $100 \mathrm{~nm}$, which is favorable to reinforce the matrix.

\section{References}

1 Feng G H, Yang Y Q, Li J et al. Rare Metal Materials and Engineering[J], 2014, 43(9): 2049 (in Chines)

2 Hill D, Banerjee R, Huber D. Scripta Materialia[J], 2005, 52: 387

3 Liu Y M, Xiu Z Y, Wu G H et al. Rare Metal Materials and Engineering[J], 2010, 39(7): 1152 (in Chines)

$4 \mathrm{Ni}$ D R, Geng L, Zhang J et al. Materials Science and Engineering[J], 2008, A478: 291

5 Zhang X H, Xu Q, Han J C et al. Materials Science and Engineering[J], 2003, A348: 41

$6 \mathrm{Yu} \mathrm{Y,} \mathrm{Li} \mathrm{C} \mathrm{L,} \mathrm{Fu} \mathrm{Y} \mathrm{Y.} \mathrm{Rare} \mathrm{Metal} \mathrm{Materials} \mathrm{and} \mathrm{Engineering[J],}$ 2014, 43(12): 2908 (in Chines)

7 Feng H B, Jia D C, Zhou Y. Journal of Materials Processing Technology[J], 2007, 182: 79

8 Lee H B, Kim S H, Kang S W et al. British Ceramic Transactions[J], 2003, 102: 231

9 Bhaskar U K, Bid S, Pradhan S K. Journal of Alloys and Compounds[J], 2011, 509: 620

10 Turkdogan E T. Physical Chemistry of High Temperature Technology[M]. Beijing: Metallurgical Industry Press, 1980

11 Fan G J, Fu L F, Qiao D C et al. Scripta Materialia[J], 2006, 54: 2137

12 Suryanarayana C. Progress in Materials Science[J], 2001, 46: 1

13 Cocco G, Soletta I, Battezzati L et al. Philosophical Magazine Part $B[\mathrm{~J}], 1990,61: 473$

14 Lee C H, Kwon Y S. Metals and Materials International[J], 2002, 8(2): 151

15 Koch C C, Whittenberger J D. Intermetallics [J], 1996, 4(5): 339

16 Fecht H J. Zeitschrift für Metallkunde[J], 2003, 94(10): 1134

\title{
球磨工艺对原位合成纳米级 TiB 的影响
}

\author{
刘利萍 ${ }^{1,2}$, 刘勇兵 ${ }^{1}$, 姬连峰 ${ }^{1}$, 曹占义 ${ }^{1}$, 杨晓红 ${ }^{1}$ \\ (1. 吉林大学 汽车材料教育部重点实验室, 吉林 长春 130025) \\ (2. 长春职业技术学院, 吉林 长春 130033)
}

摘 要: 球磨工艺对球磨粉末及其烧结组织的微观结构和形态都有重要的影响。本实验采用低能和高能球磨 2 种方式对 Ti-7Al-0.2B (质 量分数, \%) 合金粉末进行球磨, 研究球磨过程中粉末组织和形态的变化, 并将球磨后的粉末进行热压烧结, 研究不同球磨方式对烧结 组织中原位合成 TiB 增强相形态的影响。研究结果表明: 低能球磨过程中, 粉末颗粒间有机械合金化发生, 其烧结组织中生成的 TiB 为 细长态, 在基体中分布均匀, 没有联结的粗晶或成簇生长现象。对于高能球磨, 粉末颗粒细化效果明显, 颗粒平均尺寸降至 $1 \mu \mathrm{m}$, 球 磨过程中除了机械合金化还形成了 $\mathrm{Ti}(\mathrm{Al})$ 过饱和固溶体, 并在球磨后期形成了非晶结构。经高能球磨的粉末烧结后, 组织中生成了均匀 分布的纳米级 $\mathrm{TiB}$ 晶须。

关键词: 球磨; 热压烧结; $\mathrm{TiB}$ 晶须

作者简介: 刘利萍, 女, 1979 年生, 博士生, 吉林大学材料学院 汽车材料教育部重点实验室, 吉林 长春 130025, 电话: 0431-84602956, E-mail: look_see@163.com 